\title{
Ontologia, Metodologia e Prioridades nos Estudos de Defesa ${ }^{1}$
}

\section{Ontology, Methodology and Priorities on the Defense Studies}

Rev. Bra. Est. Def. v. 2, nº 2, jul./dez. 2015, p. 87-106

ISSN 2358-3932

\section{ANTONIO JORGE RAMALHO DA ROCHA}

Este artigo combina as reflexões de um assíduo estudante de Relações Internacionais com a vivência de um professor que acumulou alguma experiência na gestão pública. Uma das vantagens da vida acadêmica é que a cada dia reduzimos a nossa ignorância, o que é gratificante, mesmo sabendo que jamais conheceremos tudo o que é relevante e útil - para não falar do que julgamos apenas interessante.

É assim a vida. Sabendo levar, dizia o Barão (de Itararé, claro), é bem melhor do que a morte.

Dividi minhas observações em pequenas seções, a bem da brevidade, “irmã do talento", como nos lembrava Tchecov. Se não alcanço o talento, com disciplina imponho-me a brevidade. Já é algo. Em busca de leveza, reduzi as citações, mas compartilho uma lista de referências para os que quiserem se aprofundar nesses assuntos.

\section{$* * *$}

Em suas pesquisas, o professor José Miguel Árias registrou debates parlamentares brasileiros, em meados do século XIX, em torno dos assuntos examinados nos periódicos europeus que tratavam de política internacional. Lembrei-me das crônicas de Machado de Assis sobre o Velho Senado. Quem não as leu, não sabe o que está perdendo.

Que inveja daqueles tempos!

Não sei o que acontecerá hoje a quem oferecer aos nossos parlamentares revistas especializadas no exame das questões de segurança internacional. Nossos parlamentares não parecem interessados em política internacional. É o Parlamento que temos. Ninguém ali foi nomeado, e quero crer que re-

Antonio Jorge Ramalho da Rocha - Doutor em Sociologia (USP) e professor de Relações Internacionais (UnB/ESUDE). E-mail: antonio.ramalho@gmail.com. 
presenta, em alguma medida, as preocupações de nossa sociedade, entre as quais as políticas externa e de defesa jamais foram prioritárias.

Examino, neste artigo, questões ontológicas e metodológicas em nossa área, com a esperança de engajar os colegas mais jovens no debate sobre essa dimensão mais abstrata de nosso campo de estudos.

Tratarei brevemente da evolução desse campo no Brasil e o papel que a ABED pode desempenhar, compartilhando o que pude observar, nesses anos, do funcionamento do Ministério da Defesa. Agrego à perspectiva acadêmica, a de um observador comprometido em contribuir para consolidar em nossa sociedade uma comunidade de especialistas em Estudos de Defesa. E termino propondo eleger uma prioridade em nossa agenda: o apoio à criação de uma carreira civil no Ministério da Defesa.

\section{A CONSTITUIÇÃO DE AGENTES POLÍTICOS NO CAMPO DA DEFESA: PRIMEIRA OBSERVAÇÃO ONTOLÓGICA}

Comecemos pela ontologia de nosso campo de estudos. Vivemos hoje em um período de muita confusão. Não por acaso, adjetiva-se o conceito de guerra, na literatura especializada. ${ }^{2}$ Fala-se de guerra irregular, de conflitos assimétricos, de guerra de quarta geração, etc. Busca-se compreender a essência da guerra moderna - para alguns, a da pós-moderna -, ou da guerra do futuro, presumindo que os fundamentos tradicionais dos conflitos entre as comunidades políticas perderam relevância.

Não perderam.

As questões de defesa e segurança internacional sobre as quais nos debruçamos tradicionalmente apenas ficaram mais complexas desde o fim da Guerra Fria. Prevalece, em nossa comunidade, o consenso de que o pensamento político e jurídico moderno - e, para muitos, a própria ordem internacional contemporânea - se distingue pela assunção, pelos Estados, do monopólio sobre a Guerra. Essa relocalização da violência organizada entre comunidades políticas no plano dos Estados nacionais levou inclusive à criação de um corpo de leis da Guerra (Jus Belli ac Pacis), mas não retirou de outros grupos organizados a capacidade de empregar a força em busca de seus interesses.

Ocorre que a necessidade de contra-arrestar a violência oriunda de agentes não estatais, por mais relevante e urgente, não constitui uma guerra. A retórica política, compreensível no plano da ação diplomática ou militar, não deve ser apropriada acriticamente nas discussões acadêmicas.

Conto-lhes dois casos recentes dessa confusão conceitual, que impactam objetivamente a realidade internacional e ilustram, em linha com os 
argumentos oriundos da "virada linguística" em nosso campo, o processo de coconstituição de agentes e estruturas no ambiente internacional. ${ }^{3}$

O primeiro foi a reação do governo francês aos trágicos atentados em Paris. Não faz sentido declarar guerra a um conceito ou a uma tática de combate (Guerra ao terror ou ao terrorismo); não é inteligente fazê-lo a um grupo de poder que almeja justamente se legitimar como uma entidade de pleno direito no ambiente internacional. Um grupo que busca novos seguidores e se autointitula, contraditoriamente, um Estado Islâmico.

Há grande diferença entre o chamado Estado Islâmico e a Al Qaeda. Embora se declare interessado em fundar um califado - uma entidade política que não reclama uma base territorial, mas apenas a legitimidade de seus integrantes, para se estabelecer -, o Estado Islâmico também se apresenta como um candidato a Estado.

A Al Qaeda é diferente, pois, sendo uma ideia, está em toda parte. Isso lhe confere enorme influência, e não é casual o movimento do Estado Islâmico no sentido de começar a operar também nesses moldes, embora não exclusivamente. ${ }^{4}$

Ora, a maneira mais eficaz de se ajudar um grupo de poder a se transformar em um Estado nacional é declarar-lhe guerra. A França caiu na armadilha do Estado Islâmico, interessado em ser reconhecido como ator no ambiente internacional. Mais que os atentados de Paris, a resposta do governo francês o aproximou desse objetivo.

Quando um Estado tradicional, com a influência que tem a França, adota essa postura, ele contribui para constituir o que poderia ser considerado um grupo insurgente, uma entidade paraestatal, ou mesmo uma organização criminosa, em um candidato a um Estado nacional.

Essa não é uma maneira eficaz de se reagir a um atentado terrorista.

Ao declarar guerra, empregando força dimensionada para contra-arrestar ameaças advindas de outros Estados nacionais contra um grupo de poder, como o Estado Islâmico, a França foi além de chamar a atenção para a causa defendida por esse grupo. Ela também contribuiu para difundir, mundo afora, a mensagem que seus líderes queriam veicular: a de que eles podem restabelecer, em um ambiente westfaliano, uma forma de organização política típica de arranjos do passado.

Trata-se de erro político, influenciado pela confusão conceitual a que me referi, provavelmente motivado pela percepção da necessidade de responder prontamente a uma agressão sofrida.

A França elegeu um inimigo cujas ações podem se manifestar a qualquer momento e em qualquer lugar, o que a obriga a manter-se em guarda permanentemente, a custos obviamente insustentáveis no longo prazo. Essa guarda permanente pode ser vã, ademais, dado que um próximo 
ataque pode simplesmente jamais se realizar. Mas a sangria imposta pela necessidade de se defender em todos os momentos e espaços é certa, e influenciará o debate político interno da França.

Em parte, esse erro decorre da decisão de haver declarado guerra a uma entidade cuja natureza se distingue da de um Estado, pois sua localização não é discreta e sua liderança não se restringe a um grupo organizado, baseado em um espaço territorial conhecido. Então não há um inimigo a derrotar, um objetivo a conquistar, uma possibilidade clara de se encerrar o conflito, seja com derrota, seja com vitória.

Ademais, o chamado Estado Islâmico possui um projeto de longo prazo capaz de inspirar seguidores em várias partes do mundo, inclusive na França, prejudicando a coesão da sociedade francesa.

Ou seja, é provável que a França repita o erro dos Estados Unidos: estender um conflito por longos anos, exaurindo seu tesouro, sem chegar a resultado satisfatório do ponto de vista da segurança de sua população.

Esse tipo de ameaça se combate mais com inteligência e cooperação do que com a força; e é contraproducente declarar guerra a quem a perpetra.

Mas tampouco é fácil oferecer uma resposta pronta e eficaz a semelhante agressão, o que explica o erro.

O outro caso recente que merece atenção foi a resposta do governo espanhol aos atentados de Madri. Com todos os problemas que à época tinha o governo Aznar, sua resposta foi pragmática, embora parcialmente equivocada. Aznar errou ao tentar associar os ataques ao ETA - e argumenta-se que perdeu a eleição por isso -, mas não cedeu à tentação de promover a causa dos terroristas. ${ }^{5}$ Sua reação específica aos atentados foi inteligente, ao retirar o conteúdo político do ato, ao esvaziar a intenção dos terroristas de mobilizar a sociedade em torno de sua causa, ao tratá-los como criminosos comuns.

Com isso, sinalizou aos possíveis perpetradores de atentados terroristas que eles não alcançariam seu objetivo precípuo: expor-se à mídia, chamando atenção para sua causa com atos violentos. O recado foi o de que essa tática implicaria o emprego da polícia e o tratamento dispensado a criminosos comuns. Isso desestimulou os ativistas a recorrer ao terror para alcançar seus objetivos políticos.

Sabiamente, os governos que se sucederam não mudaram essa linha de ação.

Se é assim, a resposta francesa, além de ineficaz, ilustra a confusão conceitual no seio das lideranças políticas atuais, que, em alguma medida, obscurece o debate sobre questões de segurança nacional.

Em síntese, tenhamos claro que as visões tradicionais de emprego da força armada por uma entidade política constituída contra a de outra entidade 
política permanece importante, como nos recordam os acontecimentos cotidianos no Oriente Médio, no Mar do Sul da China, das fronteiras da Europa.

Mas é fato que as fontes de ameaças se multiplicaram, o que obrigará os Estados a desenvolver outros instrumentos para enfrentá-las.

Em vez disso, frente às dificuldades para identificar os meios apropriados a reagir às ameaças que enfrentam, os governos empregam o instrumento militar em situações que vão muito além daquelas para as quais se dimensionaram as forças armadas dos Estados nacionais.

Em que medida nossos estudos podem contribuir para evitar erros dessa natureza? Como podem os governos identificar seus inimigos e bem dimensionar suas ações? A seção seguinte aprofunda esse debate.

\section{TERRITÓRIOS, GUERRAS E OUTROS CONFLITOS NO CAMPO DA DEFESA: SEGUNDA OBSERVAÇÃO ONTOLÓGICA}

Nosso campo de estudos abriga um conjunto de aproximações discursivas, inclusive metodologicamente distintas entre si, favorecendo o diálogo interdisciplinar. Não praticamos uma disciplina no sentido tradicional, centrada no emprego de um paradigma (ou no confronto de vários candidatos a paradigmas de análises); nosso campo de estudos, por definição, está aberto a contribuições de várias disciplinas de pensamento.

Aquilo que se caracteriza como Estudos de Defesa compartilha objetos, conceitos e métodos com o campo das Relações Internacionais. O professor Eugênio avançou parte do que diria, e o fez melhor do que eu faria. Mas permitam-me recordar aspectos relevantes para se compreender a ontologia do nosso campo.

O primeiro foi sublinhado, há décadas, por Quincy Wright (1942), em seu estudo sobre a guerra. Eram tempos de violência, marcados pelos processos de independência na África e na Ásia. Wright caracterizava a guerra como apenas uma espécie de conflito, a interação violenta (com o emprego de força de considerável magnitude) entre grupos de poder, entre comunidades políticas. ${ }^{6}$ Não falava de indivíduos, mas de coletividades que se organizam à luz de uma autoimagem, de identidades socialmente construídas, tanto em sua mútua interação quanto na interação dos indivíduos que as integram, os quais com ela se identificam e, nesse processo, constroem sua própria identidade.

É o que sói acontecer com os Estados nacionais, mas não apenas com eles. Trata-se de um processo complexo, em que se empregam narrativas destinadas a tornar possível aos indivíduos conceber-se, e apresentar-se, como constituintes dessas entidades coletivas, como seus promotores e defensores. 
Por essas mesmas narrativas, diferenciam-se umas coletividades das outras, e, gradualmente, define-se a substância de suas interações, que não são necessariamente conflituosas. Há também cooperação, que, aliás, se observa até mesmo em plena guerra, mediante diálogos, tréguas, negociações e, eventualmente, armistícios.

Do ponto de vista ontológico há, pois, pelo menos três elementos-chave no debate contemporâneo sobre segurança e defesa, relevantes para a nossa discussão. As coletividades que interagem mutuamente, de forma cooperativa e conflituosa; o grau de legitimidade dessas entidades e de sua base territorial; e os processos de sua constituição como atores políticos. Esses processos se inter-relacionam, e merecem atenção detida.

Vejamos a questão do empenho em se afirmar politicamente. As interações que nos interessam aqui envolvem pelo menos uma entidade politicamente constituída. Normalmente, quem não está constituído como Estado busca isso, dado que o ambiente internacional contemporâneo favorece os Estados em detrimento de outras coletividades. Essa constituição implica, todavia, o reconhecimento dos que já se estabeleceram. Não foi diferente no passado. As negociações conducentes ao reconhecimento da soberania das ex-colônias americanas, africanas e asiáticas ilustraram bem esse processo.

Nesse contexto, a territorialidade é uma referência importante, mas não necessária. O ressurgimento de conceitos como o de califado, que não pressupõe um território delimitado, desafia o requisito da territorialidade. $\mathrm{O}$ califado se constitui na - e pela - relação dos indivíduos que se submetem ao Califa. Mesmo nômades, dispersos em territórios de diversos Estados nacionais, esses indivíduos continuam leais ao Califa. A relação de mando, a relação de autoridade constituída, dá-se entre eles e o seu Califa.

Pensem nas implicações disso.

A territorialidade, nesse caso, é chave para situar e explicar, mas não tanto para entender, o processo político, inclusive os embates que venham a dar-se entre as partes. ${ }^{7}$ Mas ela não é necessária para explicar o fenômeno da guerra nem a afirmação do grupo de poder como entidade política reconhecida no âmbito internacional.

Um califa pode entrar em guerra contra um Estado territorialmente bem constituído, sem ter a pretensão de ocupar aquele território, de se estabelecer permanentemente naquele lugar, de controlar aquele espaço. Pelo critério de Wright, na medida em que esse Califa represente uma coletividade e seja capaz de empregar força de considerável magnitude em seus embates com outros grupos de poder, observar-se-ia uma guerra.

Mas notem que, para o Califa, pode ser suficiente conquistar os corações e mentes, a lealdade dos seus seguidores. Se é assim, ele pode ampliar 
seu poder, já que seus súditos podem ter a cidadania reconhecida pelos governos dos Estados nacionais. Isso é possível porque este senhor não apela a identidades nacionais, étnicas nem tribais, mas a um sentido de comunidade que encontra respaldo em um contex to religioso e/ou filosófico.

Há uma outra manifestação atual e relevante desse processo de "desterritorialização" da política internacional. Trata-se do emprego de identidades linguísticas como substrato de uma comunidade mais ampla. Quando o presidente Putin afirma a responsabilidade da Grande Rússia pelos que falam russo, outros governos percebem nisso uma ameaça. Se em seu território há comunidades que falam russo, então, parece haver razão para preocupar-se, especialmente depois do que ocorreu na Ucrânia.

Embora relevante, a disputa territorial não é, como se vê, crucial para se definir os conflitos, e quiçá as guerras, de hoje. As disputas de poder travam-se entre comunidades políticas organizadas, cada qual com sua visão de futuro, com uma expectativa de sua presença, de seu papel nesse futuro. Eventuais conflitos entre essas expectativas podem levar esses grupos políticos organizados a empregar a força. ${ }^{8}$

Quando se fala de Defesa, fala-se disso. Fala-se da defesa dessa comunidade por cada governo constituído, fazendo uso das armas disponíveis. Por muito tempo, pelo menos desde a constituição dos Estados nacionais, isso esteve claro; hoje não está tanto assim. Não é casual que alguns autores, em fins dos anos 1990, tenham começado a caracterizar as relações internacionais como uma nova Idade Média.

Redefinem-se as relações de poder mundo afora e há dúvidas sobre se o modelo westphaliano seguirá pautando as relações internacionais contemporâneas. ${ }^{9}$

Em outras palavras, estamos acostumados a conferir precedência analítica aos Estados nacionais bem constituídos, que se reconhecem mutuamente, com sua territorialidade, com suas fronteiras, com forças armadas profissionais em interação permanente. Estamos habituados a presumir que essa dinâmica estrutura o cenário político internacional, condicionando mais do que sendo influenciada pelas relações que envolvem outros grupos de poder. Mas esses são apenas nossos hábitos de pensamento - a verdade é que não sabemos se esse modelo prevalecerá no futuro previsível.

A perplexidade diante de transformações que podem ser tão profundas na ordem internacional decorre, em parte, da ontologia de nosso campo de estudos. Quem são os atores chave? O que os move? Que processos engendram dinâmicas coletivas - sistêmicas ou societais, conforme a abordagem conceitual - capazes de moldar o ambiente internacional e seus constituintes?

Construímos mais de uma resposta razoável para essas perguntas, o que nos leva a um debate metodológico. Passemos, então, a essa discussão. 


\section{DA RELEVÂNCIA DO MÉTODO PARA JULGAR CIENTÍFICAS AS CRENÇAS COM QUE DAMOS SENTIDO AO MUNDO}

Recupero, aqui, a questão metodológica que lhes prometi examinar.

Ainda não encontrei argumento mais claro e conciso sobre o assunto do que o do filósofo Alfred North Whitehead (1929), para quem a produção de conhecimento científico consiste em apenas uma das funções da razão. Para ele, as narrativas científicas devem submeter-se a um conjunto de critérios específicos, a fim de se validarem nessa condição.

$\mathrm{O}$ fato de atenderem a estritos critérios metodológicos, contudo, não lhes retira a condição de uma narrativa convalidada inter-subjetivamente, de uma crença especial.

Segundo Whitehead, os discursos que produzimos sobre a realidade, para serem considerados científicos, necessitam atender simultaneamente a pelo menos quatro critérios básicos:

(1) O primeiro é a clareza do conteúdo da exposição: o discurso deve ser claro, articulado, compreendido e compreensível pelos que falem o idioma no qual se expressa uma crença científica. Não pode ser uma narrativa obscura, hermética, que se pretenda sofisticada porque os ouvintes ou leitores não a compreendem (já se vê que isso é algo difícil para muitos de nossos colegas, especialmente em áreas como Economia e Direito).

(2) O segundo critério é a consistência lógica interna das categorias analíticas empregadas na construção da narrativa. Os conceitos devem conviver uns com os outros do ponto de vista lógico; o discurso não pode ser contraditório.

(3) O terceiro é a consistência lógica externa também: o discurso não pode ser negado por outras narrativas que também interpretam os mesmos fenômenos da realidade, sob pena de perder credibilidade.

(4) Por fim, impõe-se a questão empírica: o que se afirma sobre a realidade deve possuir ampla conformidade com o que se observa. Tanto o narrador quanto seus interlocutores devem constatar a correspondência entre o que se afirma acerca dos processos em exame e a observação fática da realidade. Da mesma forma, não se deve observar qualquer discrepância profunda daquela narrativa, pois, como demonstrou Popper, basta um cisne negro para demonstrar falsa a assertiva, corroborada milhões de vezes, de que todos os cisnes são brancos.

Em outras palavras, para ser validada por uma comunidade científica, o discurso deve atender pelo menos a esses critérios. $\mathrm{O}$ argumento de Whitehead acerca da validação de argumentos nas ciências humanas e sociais aplicadas é, a meu ver, mais sólido do que o de Weber, embora ambos realcem a importância do método como critério de validação do discurso 
científico e se preocupem com a consistência lógica dos discursos e com sua comprovação empírica.

Como nos ensina o professor Saint-Pierre, em seu excelente ensaio sobre Weber, a "validade e a objetividade passam a ser propriedades metodológicas: a validade do conhecimento científico dependerá da objetividade dos métodos empregados." Essa validade dependerá "de que a estrutura lógica destes [métodos] possa garantir a verdade dos enunciados observacionais às hipóteses e vice-versa, pois por essa via se poderá cumprir o requisito fundamental da objetividade científica exigido por Weber: a verificação empírica dos resultados obtidos" (Saint-Pierre, 2009 [2004], p. 21).

Em outras palavras, Weber crê em que, ao se empregar apropriadamente o método científico, pode-se estabelecer uma verdade científica universal, validada pela lógica e pela empiria. Whitehead, por seu turno, ressalta que a consistência lógica do discurso não lhe confere valor de verdade; apenas lhe assegura uma estrutura de enunciados válidos, que, como nos demonstram há milênios os silogismos, podem ser falsos.

O corolário de seu argumento é o de que, na medida em que atendam a esses critérios, discursos concorrentes podem coexistir e ser considerados científicos.

Trata-se de uma postura mais humilde com relação à capacidade humana de produzir ciência acerca de sua própria experiência, a qual realça a virtude da confrontação de narrativas científicas.

Ademais, insiste em que, mesmo que as narrativas válidas logicamente sobrevivam ao teste empírico, não se lhe deve conferir valor de verdade absoluta; mas apenas o de uma verdade provisória, um consenso a que se chega com os artifícios lógicos de observação da realidade disponíveis.

Whitehead enfatiza, pois, o caráter consensual e intersubjetivo da produção do conhecimento científico, enquanto Weber preocupa-se mais com a distinção entre os diferentes papéis desempenhados pelo homem de ciência, ao ressaltar a necessidade de se distinguir claramente os argumentos que falam ao intelecto dos que falam à razão (Weber, 1982). Ou seja, o foco de Weber recai nas operações mentais de cada pensador, enquanto o de Whitehead, sem negar a necessidade dessa distinção entre as operações mentais e suas consequências para a ação do indivíduo, salienta a dimensão social da produção científica.

Afinal, é por isso que publicamos nossos achados, que nos educamos nesses discursos, que aprendemos a empregar propriamente seus conceitos, de modo a legitimarmos as narrativas que nos permitem conferir sentido, coletivamente, à realidade em que vivemos.

Assim reconstruímos, no plano discursivo, de forma disciplinada, por critérios lógicos e empíricos, e mediante sua confrontação com outras nar- 
rativas científicas sobre os mesmos fenômenos da realidade, uma interpretação válida do mundo que examinamos. É isso o que distingue a crença científica da não científica.

Mas observem que ambas são crenças. A diferença está em que uma é validada, ou aprovada, por uma comunidade supostamente conhecedora - logo, autorizada a validar - dos métodos apropriados para se produzir ciência. Outras narrativas se sujeitam a outros conjuntos de critérios (estéticos, dogmáticos, etc.), obviamente, empregados em suas respectivas comunidades epistêmicas.

Com esses critérios, Whitehead nos dá uma lição de humildade. Devemos aproveitá-la. Não se produz conhecimento apenas pelos métodos científicos. Também na literatura, nas artes e na própria religião é possível produzir conhecimento relevante sobre o mundo e sobre a humanidade. Vocês confiariam em um psicólogo que não conhece Dostoievsky, Machado de Assis ou Shakeaspeare?

Eu não.

Whitehead sublinha, enfim, que a ciência se faz de uma maneira específica, mas que não deixa de produzir implicações éticas e morais. Afinal, esses consensos influenciam o modo como as pessoas pensam sobre a realidade e, por conseguinte, suas ações. Quem não se lembra dos argumentos racistas baseados em teorias eugênicas, que influenciaram tanta gente e produziram tantas desgraças no século passado?

$\mathrm{Na}$ medida em que as pessoas acreditam em que a realidade funciona daquela maneira específica, elas atuam nessa - e sobre essa - realidade em função de suas crenças; portanto, de modo enviesado, porque informado por essa leitura da realidade. ${ }^{10}$

A implicação lógica desse processo é que, pelo menos no plano das interações humanas - de que tratam as ciências humanas e sociais aplicadas, ou as ciências da "cultura", como se dizia antigamente -, pode ser que a realidade tenha adquirido a dinâmica observada não por causa de sua natureza intrínseca, mas devido a processos desencadeados pelas crenças compartilhadas entre os seres humanos acerca dessa realidade e de seu lugar nela.

Keynes, aliás, já nos lembrava de que políticos de hoje sempre agem, saibam disso ou não, em conformidade com o que algum teórico, decerto falecido há muito, disse da realidade em que vivemos.

O poeta Mario Quintana dizia o mesmo, mais suavemente: "Os livros não mudam o mundo, os livros mudam as pessoas. As pessoas mudam o mundo”.

Então, se vocês quiserem exercer influência sobre as pessoas, escrevam livros que mudem a forma como as pessoas veem o mundo.

O que espanta nessa discussão é o fato de tantos intelectuais sustentarem, com base em suas convicções, a pretensão de neutralidade nas ciên- 
cias humanas. Neutralidade não existe no campo das ciências humanas; e é possível argumentar que tampouco exista no campo das ciências exatas e biológicas. Apenas as ciências formais, a lógica e a matemática, se marcariam por discursos intrinsecamente neutros, o que não assegura que suas aplicações se farão com imparcialidade. Mas essa é outra discussão, que nos levaria a debates mais abstratos, incongruentes com este fórum.

As intervenções narrativas que produzimos, não importa quão rigorosas, contribuem seja para manter, seja para transformar a realidade. Elas são apropriadas pelos atores políticos, cujas narrativas tendem a ser menos precisas e rigorosas do que as científicas. Afinal, sem ambiguidades linguísticas não se produzem acordos políticos.

Recai sobre nós, analistas, a responsabilidade de articular discursos que permitam tratar com maior transparência os fenômenos sobre os quais se atua, deixando claras as posições de cada ator envolvido nos processos de negociação - inclusive as nossas, ao explicitar nossos valores, como bem recomendava Weber.

Ao fazê-lo, contribuímos para que a sociedade se eduque e possa decidir conscientemente sobre seus destinos, iluminada também pela razão científica. Devemos estar conscientes, contudo, de que nem sempre as evidências científicas prevalecem, como as negociações sobre mudança climática tão bem ilustram.

Mas, ao termos clara a ontologia do nosso campo e a necessidade de se empregar rigor metodológico na construção de nossos discursos, estamos fazendo a nossa parte. A consolidação da área de Estudos de Defesa no Brasil requer um debate científico sofisticado, que contribua para instruir e capacitar nossa sociedade a, consciente e responsavelmente, tomar decisões políticas nesse campo.

A próxima seção discute o papel que deve ter uma associação científica como a nossa no campo da defesa.

\section{DO FOMENTO AOS ESTUDOS DE DEFESA, DA INSTITUCIONALIZAÇÃO DO MINISTÉRIO DA DEFESA E DO PAPEL DA ABED}

O debate encetado neste artigo produz consequências para a consolidação dos Estudos de Defesa no Brasil. Tanto do ponto de vista ontológico, quanto do metodológico, os desafios enfrentados pelos Estudos de Defesa não diferem dos que avultam em campos conexos, como Ciência Política e Relações Internacionais.

Entretanto, um dos temas em debate neste e em outros encontros setoriais da $\mathrm{ABED}$ envolve a criação de comitês de área que se dediquem exclusivamente aos temas de defesa. Muitos de nós trabalhamos para criar, no 
CNPq, um comitê de área. Logramos apenas criar um comitê temático, que teve vida breve, a cuja extinção nos opusemos publicamente, eu e o professor Eliézer Rizzo, infelizmente sem êxito. Éramos poucos, então, e o CNPq não enxergou a necessidade de investir por mais tempo na consolidação dessa área. Mais recentemente, a autarquia voltou atrás, por iniciativa do Instituto Pandiá Calógeras, ao lançar o edital Álvaro Alberto.

Posições divergentes acerca desses comitês indicam, na verdade, disputas por recursos de fomento a pesquisas, as quais expõem a natureza cartorial da estrutura de fomento à pesquisa hoje em voga no Estado brasileiro. É certamente necessário mudar essa dinâmica, mas isso vai além das capacidades de nosso campo de estudos.

A verdade é que, dos pontos de vista ontológico e metodológico, o que fazemos não difere substancialmente do que se faz nos campos das Relações Internacionais e da Ciência Política. Se é assim, convém explicitar a posição que nossa associação quer adotar sobre o assunto, pois não se trata apenas de uma questão técnica. Trata-se também de adotar uma posição ética, com implicações políticas.

A meu ver, uma associação científica deve posicionar-se a favor de um debate que se fundamente no mérito dos discursos científicos que empregamos para dar sentido ao mundo, os discursos que ajudamos nossos alunos a aprender. Os recursos devem destinar-se aos projetos que sejam mais robustos em termos teóricos, mais rigorosos em termos metodológicos, mas inovadores em sua capacidade de interpretar aspectos relevantes da realidade em que vivemos. Projetos que levem a resultados consistentes em seu papel de orientar a ação política.

É por isso que continuamos estudando relações internacionais ao longo de nossas vidas, com o mesmo empenho, com a mesma humildade, com a mesma vontade de produzir interpretações que sejam a um tempo rigorosas e consequentes para a realidade em que vivemos.

Ao fazê-lo, nossa associação se legitima como ator relevante nesse debate, um debate que não terá fim, pois a natureza do que estudamos é velha como a Humanidade. Continuaremos vivendo em grupos e essas coletividades continuarão engendrando conflitos no porvir. Hoje entendemos melhor a natureza desse processo, inclusive porque aprendemos a empregar métodos adequados na construção de nossas narrativas sobre a realidade internacional.

Na medida em que se firma com autoridade na promoção desse debate, a ABED contribui para que ele se aperfeiçoe e para que saibamos equacionar melhor o tipo de relação entre civis e militares que queremos construir nesse longo processo de transição para a democracia pelo qual a sociedade brasileira vem passando. 
Não quero concluir minha fala sem uma reflexão acerca do amadurecimento institucional do Ministério da Defesa.

Discuti questões ontológicas e metodológicas de nosso campo; realcei a importância de a ABED posicionar-se claramente sobre a importância de critérios metodológicos como base da distribuição de recursos para a pesquisa em nosso país. Felizmente, a qualidade das pesquisas na área vem melhorando a cada ano, assim como a formação de mestres e doutores, que se expande e sofistica continuamente. Pouco a pouco, nossa comunidade ganha massa crítica e começa a participar ativamente no processo decisório, ainda tão hermético nesse campo.

Nesse contexto, se há uma bandeira a levantar, se há uma causa a eleger como prioritária, essa deve ser a criação de uma carreira de Estado no Ministério da Defesa.

Hoje, ainda prevalecem, na conformação de nossas políticas de Defesa, visões parciais, das três Forças, confluindo, em maior ou menor harmonia, conforme o assunto, para se implementar a política e a estratégia nacional de defesa. A formação de nossos militares ainda se faz do ângulo de suas respectivas Forças, e é natural que seja assim. Essas coisas levam tempo para mudar. Levaram muito tempo para mudar no mundo inteiro e aqui não será diferente. ${ }^{11}$

É por isso que se deve explicitar e examinar a resistência à criação dessa carreira. Para ter a capacidade de conduzir politicamente o setor de defesa no Brasil, o Ministério da Defesa necessita que se estabeleça uma carreira de Estado, integrada por servidores capacitados em assuntos de defesa e dedicados, em caráter permanente, a implementar as prioridades nacionais nesse setor. Servidores que guardem a memória da instituição, que tenham um plano de cargos e salários razoável e a perspectiva de dedicar sua vida profissional a esse setor. Servidores que sejam capazes de se relacionar em pé de igualdade com os militares, conhecendo-lhes as especificidades, respeitando-lhes os valores e os pontos de vista, convencendo-lhes da necessidade de caminharmos juntos na direção de criar uma cultura de defesa em nosso país.

Observe-se que uma carreira civil não deve espelhar a formação do militar. Não se deve ter a expectativa de que os concursados para essa carreira, sejam eles civis ou militares, só terão condições de influir nas decisões da pasta depois de 25 ou 30 anos.

É óbvio que as posições superiores demandarão largo tempo de formação, a fim de que os servidores adquiram o conhecimento e a experiência necessária para bem ponderar decisões em um campo tão sensível. Mas isso não 
significa que os jovens servidores devam se restringir a tarefas operacionais ou táticas nos primeiros 10 ou 15 anos de carreira. $\mathrm{O}$ tipo de aprendizado que eles precisam realizar e as competências que precisam desenvolver requer exposição a decisões estratégicas desde o princípio de sua carreira.

Antes de discutir suas características, é preciso criar a referida carreira. $\mathrm{E}$, para tanto, há que se vencer a silenciosa, mas eficaz, resistência burocrática a essa decisão. Isso é natural; é de se esperar que quem ocupa as posições administrativas a serem preenchidas pelos servidores concursados não queira ser desalojado. Também seria muito estranho encontrar nas Forças Armadas um forte interesse em criar uma carreira que lhes diminuísse a autonomia decisória, por mais que haja nas Forças quem perceba a importância de fazer prevalecer critérios de interoperabilidade, maior ênfase no preparo conjunto, economias de escala na gestão administrativa, enfim, uma série de aperfeiçoamentos necessários a melhor aprestar as tropas para cumprir sua missão constitucional.

Contudo, entre essa visão do que é necessário no futuro e as pressões de curto prazo, estas tendem a prevalecer, especialmente quando se observa intensa rotatividade das lideranças seniores no Ministério, inclusive dos ministros.

A bem da verdade, essa resistência vem sendo matizada, uma vez que os próprios militares já se deram conta da necessidade de pensar a defesa de forma integrada. $\mathrm{O}$ fato de muitos oficiais-generais terem passado pelo MD levou-os a conhecer melhor as características das outras Forças, além de haverem criado laços de amizade e camaradagem com seus colegas das Forças irmãs. Hoje, os altos-comandos tem visão de conjunto, em contraste com o que ocorria há alguns anos.

Em um passado não muito distante, para vocês terem uma ideia, nossas Forças trabalhavam com hipóteses de emprego específicas, diferentes umas das outras. Eu vi isso. Na época, imaginava como elas articulariam esforços caso o Brasil entrasse em um conflito real. Hoje, isso não existe mais; há uma visão integrada dos cenários, há uma experiência acumulada de exercícios conjuntos, há mais conhecimento compartilhado sobre as práticas utilizadas em cada uma das Forças. Ainda precisamos avançar na criação de comandos conjuntos e na harmonização geográfica dos comandos setoriais, mas já houve progresso nesse sentido.

O grande desafio é, pois, o de institucionalizar a carreira de defesa, criando um ambiente de plena confiança entre civis e militares. Todos temos de fazer nossos respectivos deveres de casa com relação a isso, de modo a construir confiança entre as novas gerações de civis e militares.

Por isso, acho tão importante ver na plateia jovens estudantes interessados em participar desse processo. 
Um dos problemas que enfrentamos para construir esse ambiente de confiança tem que ver com o que considero um hiato de percepção entre as elites civis e militares.

Examinem-se as percepções sobre o regime militar, por exemplo. Se vocês conversarem com os chefes de hoje, oficiais-generais de três, quatro estrelas, vocês verão que eles têm dificuldade em compreender porque isso ainda é um assunto tão debatido e tão controverso, como evidenciou o processo conduzido pela Comissão da Verdade, a um par de anos. Para eles, isso é coisa do passado. Quem tinha alguma capacidade de decisão naquela época ou já faleceu ou está na reserva há muito tempo. Por força da lei de carreiras, de 1965, houve uma renovação das elites militares.

Para as elites civis, contudo, isso ainda é presente. Líderes influentes no setor privado, na mídia, na academia, nas artes e na política viveram aqueles tempos. No Brasil, civis e militares percebem de forma diferente esse período histórico. Se não entendermos isso, será difícil engajarmo-nos em um diálogo franco, construtivo, que permita à sociedade deixar o passado em seu lugar e inaugurar uma nova fase na relação cívico-militar em nosso país. Uma relação que, não é demais lembrar, historicamente sempre foi muito intensa e rica.

Chamei a atenção de vocês com exemplos de temas sabidamente controversos, a carreira civil no MD e a relação entre civis e militares em nossa sociedade. Ambos carecem de exame sistemático, de análises científicas que nos permitam melhor compreender a dinâmica observada na sociedade brasileira, a fim de aperfeiçoar o setor de defesa em nosso Estado e de consolidar uma cultura de defesa em nossa sociedade.

Então, para concluir, eu diria que é razoável esperar resistências nesse processo de modernização institucional do Ministério da Defesa. Não o digo normativamente, isto é, não digo que deva ser assim. Também é razoável esperar que os ministros de defesa sejam cautelosos ao propor mudanças.

Basta ver a resistência que se observou à criação do Instituto Pandiá Calógeras, apenas por se tratar de uma célula de pensamento civil ligada à cúpula do MD. E olhe que estamos falando de uma estrutura modesta, que não toca em aspectos sensíveis dos interesses das Forças, podendo mesmo ser-lhes útil.

A primeira vez que eu discuti a criação de algo com essas características foi com o vice-presidente José Alencar, que, por força de uma crise política, acumulou temporariamente o Ministério da Defesa. Ele achou uma boa ideia, mas, ao perceber a enorme resistência à ideia, mineiramente deixou-a de lado.

$\mathrm{O}$ ex-ministro Jobim retomou o assunto, com sua proverbial assertividade. Houve um movimento para instalar o Pandiá no seio da ESG, o que lhe retiraria tanto o caráter civil quanto a autonomia de pensamento. Não 
fosse o fato de a ESG possuir características de uma organização militar e a ideia do Pandiá ser a de um think tank civil, é provável que o Instituto não houvesse sido criado ou que houvesse sido absorvido pelo Centro de Estudos Estratégicos da ESG.

Mesmo havendo tomado a decisão, o ex-ministro Jobim não conseguiu implementá-la. Foi preciso um diplomata para recuperar o projeto e levá-lo adiante, depois de quase oito anos. E, prestem atenção, o Pandiá ainda não se firmou inteiramente. Faltam-lhe cargos, pessoal, orçamento, autonomia. $\mathrm{O}$ ideal é que ele funcione como um desses institutos vinculados ao MCTI (O IMPA, o CGEE, o INPE), que possuem uma lei própria, uma carreira própria, um corpo muito pequeno de pesquisadores muito qualificados, capazes de se relacionar com a elite do pensamento mundial no campo da segurança e defesa.

Mas isso não poderia acontecer agora, por falta de massa crítica em nossa área. Isso é um processo. Daqui a alguns anos, depois que o Pandiá mostrar serviço, ficará claro que o país precisa de um órgão com essas características.

\section{À GUISA DE CONCLUSÃO}

Este texto resulta de uma comunicação em um seminário destinado a debater temas tão diversos quanto o papel da ABED na institucionalização da área de defesa no Brasil, as experiências colhidas ao longo do extenso processo de criação de uma comunidade de Estudos de Defesa em nosso país e questões abstratas ligadas à ontologia e aos métodos empregados em nosso campo de estudos.

Não se poderia esperar dele, portanto, uma estrutura argumentativa simples ou direta, a demonstração de uma tese. Ao contrário, tratava-se de responder às demandas dos organizadores deste evento e de levantar questões que me parecessem, à luz do debate aqui realizado, importantes para pensarmos o nosso campo de estudos.

Não obstante, o bom nível de debates e a alta qualidade intelectual da plateia me permitiram elaborar um argumento que demonstra a relevância dos aspectos ontológicos e metodológicos na construção de discursos científicos sobre questões de defesa no Brasil. Mais que isso, ao sustentar a necessidade de se empregarem critérios meritocráticos como base para a alocação de recursos para o fomento à pesquisa, e então assumir posição clara com respeito à prioridade de uma carreira de defesa no $\mathrm{MD}$, a $\mathrm{ABED}$ se firmará como interlocutor chave no processo de fortalecimento da comunidade de defesa em nosso país, contribuindo para o aperfeiçoamento institucional do Ministério da Defesa. 


\section{REFERÊNCIAS}

BALDWIN, D. The concept of security. Review of International Studies, 23, p. 5-26, 1997. Disponível em: <http://www.princeton.edu/ dbaldwin/selected\%20 articles/Baldwin\%20(1997)\%20The\%20Concept\%20of\%20Security.pdf>.

BOWDISH, R. Military strategy: theory and concepts. Tese (doutorado em Filosofia). University of Nebraska, Nebraska, 2010. Disponível em: $<$ http://digitalcommons.unl.edu/cgi/viewcontent.cgi? $\operatorname{article}=1026 \&$ context $=$ poliscitheses $>$. Acesso em: 02 fev. 2015.

COOPER, R. The breaking of nations: order and chaos in the twenty-first century. London: Atlantic Books, 2003.

DUNLAP, C. Neo-strategicon: modernized principles of war for the $21^{\text {st }}$ century. Military Review, p. 42-49, mar./apr. 2006. Disponível em: <http://www.au.af.mil/ au/awc/awcgate/milreview/dunlap.pdf $>$. Acesso em: 02 fev. 2015.

EUROPEAN COMMISSION \& HIGH REPRESENTATIVE. Review of the european neighbourhood policy. Joint Communication 50 final. Brussels, EU. 2015.

FOSTER, G. A case for demilitarizing the Military. Lobelog - Foreign policy, 19 mar. 2016. Disponível em: <http://lobelog.com/a-case-for-demilitarizing-the-military>.GAL-OR, N.; GIESEN, K. G. The concept of war. Peace Review, 19: 2, p. 149-156, 2007. Disponível em: <http://www.tandfonline.com/doi/fu 1l/10.1080/10402650701353240>. Acesso em: 03 fev. 2015.

GRIFFITHS, M.; O'CALLAGHAM, T. International relations - the key concepts. London \& New York: Routledge, 2002.

HOLLIS, M.; SMITH, S. Explaining and understanding international relations. London: Clarendon Press, 1991.

HURD, I. Legitimacy and authority in international politics. International Organization, 53, 2, p. 379-408, spring 1999.

KALDOR, M.; SOLANA, J. (Ed.). From hybrid peace to human security: rethinking EU strategy towards conflict. The Berlin Report of the Human Security Study Group. London: London School of Economics and Political Science, 2016.

LASSWELL, H. D.; KAPLAN, A. Power and society. New Haven: Yale University Press, 1959.

LIPSHUTZ, R. D. On security. New York: Columbia University Press, 1995. 
MACLEAN, S. J.; BLACK, D. R.; SHAW, T. M. A decade of human security: global governance and new multilateralism. Hampshire: Ashgate, 2006.

ONUF, N. G. World of our making: rules and rule in social theory and international relations. Columbia: University of South Carolina Press, 1989.

POPPER, K. Conjectures and refutations. London: Routledge \& Kegan Paul, 1969.

REQUENA, M. (Ed.). Luces y sombras de la seguridad internacional en los albores del siglo XXI. 3 vol. Madrid: Instituto Universitario General Gutiérrez Mellado UNED, 2008.

Saint-Pierre, H. L. Max Weber: entre a paixão e a razão. Campinas: Ed. da Unicamp, 2009.

SALCH, A. Broadening the concept of security: identity and societal security. Geopolitics Quarterly, v. 6, n. 4, p. 228-241, winter 2010. Disponível em: <http:// www.sid.ir/en/vewssid/j_pdf/10802112013.pdf>. Acesso em: 05 fev. 2016.

SMITH, S.; BOOTH, K.; ZALEWSKI, M. International theory: positivism and beyond. Cambridge: Cambridge University Press, 1996.

WEBER, M. Ensaios de sociologia. Rio de Janeiro: LTC - Livros Técnicos e Científicos Editora S. A., 1982.

WHITEHEAD, A. N. The function of reason. Princeton: Princeton University Press, 1929.

WRIGHT, Q. A study of war. Chicago: Chicago University Press, 1942. 


\section{NOTAS}

1. As opiniões expressas são de inteira responsabilidade do autor e não necessariamente correspondem às posições das instituições a que ele se vincula profissionalmente.

2. Veja-se, para breves resumos, por exemplo, Bowdish (2010), Dunlap (2006), Gal-Or e Giesen (2007), Hollis e Smith (1991), Hurd (1999), Lipshutz (1995) e Salch (2010).

3. Onuf (1989) permanece a melhor referência teórica.

4. Sobre a diferença entre poder e influência, sugiro releitura (para os mais jovens será a leitura) de Lasswell e Kaplan (1959), sobretudo pela insistência na necessidade de se possuir clareza e precisão conceitual.

5. O erro de avaliação política consistiu em apostar que, no calor da campanha eleitoral, a população apoiaria um governo que se mostrasse no polo oposto ao ETA, cujos atos de violência já fatigavam a população espanhola.

6. Observem a diferença entre este conceito e o que utiliza a Convenção de Genebra: WAR: "Any difference arising between two States and leading to the intervention of members of the armed forces..." (Convention (IV) relative to the Protection of Civilian Persons in Time of War, 12 August 1949. Commentary - Article 2. Part I: General provisions).

7. Para essa diferença, que atualiza o debate metodológico alemão do século XIX e o aplica ao campo das Relações Internacionais, veja-se Hollis e Smith (1991).

8. Então, a trindade de que nos falava Clausewitz revela, uma vez mais, sua capacidade explicativa. O povo, o governo constituído e a força armada se unem em torno de um objetivo coletivo, não necessariamente restritos em um território predeterminado.

9. Cooper (2003) e Kaldor e Solana (2016), por exemplo.

10. Essa discussão é retomada tanto pelos pós-positivistas quanto pelos construtivistas, contemporaneamente. Entre os melhores textos para se inteirar do modo como se procede a essa recuperação desse debate, veja-se Smith et al. (1996) e Onuf (1989).

11. Ainda hoje se fala em crise nas relações entre civis e militares nos EUA, para se ter uma ideia. Veja-se, por exemplo, a fundada crítica de Foster (2016). 


\section{ONTOLOGIA, METODOLOGIA E PRIORIDADES NOS ESTUDOS DE DEFESA"}

\section{RESUMO}

Este artigo combina as reflexões de um assíduo estudante de Relações Internacionais com a vivência de um professor que acumulou alguma experiência na gestão pública. Uma das vantagens da vida acadêmica é que a cada dia reduzimos a nossa ignorância, o que é gratificante, mesmo sabendo que jamais conheceremos tudo o que é relevante e útil - para não falar do que julgamos apenas interessante. Dividi minhas observações em pequenas seções, a bem da brevidade, "irmã do talento", como nos lembrava Tchecov. Se não alcanço o talento, com disciplina imponho-me a brevidade. Já é algo. Em busca de leveza, reduzi as citações, mas compartilho uma lista de referências para os que quiserem se aprofundar nesses assuntos.

Palavras chave: Ontologia; Metodologia; Estudos de Defesa; Epistemologia.

\section{ABSTRACT}

This article combines the reflections of an assiduous student of International Relations with the experience of a teacher who has accumulated some experience in public management. One of the advantages of academic life is that every day we reduce our ignorance, which is gratifying, even thoughwe never know everything that is relevant and useful - not to mention that we judge just interesting. I divide my remarks into small sections, for the sake of brevity, "the sister of talent" as remembered in Chekhov. If I do not reach the talent with discipline let me be brief. It's something. In search of lightness, I have reduced the quotations, but I share a list of references for those who want to delve into these matters.

Key-words: Ontology; Metodology; Defense Studies; Epistemology. 